\title{
FERRAMENTAS DE MARKETING: ESTUDO DE CASO COM CONSUMIDORES DE SUPERMERCADOS DA CIDADE DE CARANGOLA - MG
}

\author{
MARKETING TOOLS: CASE STUDY WITH CONSUMERS OF SUPERMARKETS IN \\ CARANGOLA CITY - MG
}

\begin{abstract}
Altamiro Junior Lacerda de Almeida1, João Carlos Valente Gomes Resgala", Camila Lacerda Abreu ${ }^{3}$, Marília Miranda Lacerda ${ }^{4}$, Wagner dos Reis Marques Araújo ${ }^{5}$

${ }^{1}$ Universidade Estadual de Minas Gerais, Unidade - Carangola; Instituto Federal de Educação, Ciências e Tecnologia - Sudeste de Minas Gerais - Campus Avançado de Cataguases; Grupo UNIS Faculdades Integradas de Cataguases, Brasil email: altamiro@unis.edu.br

2 Universidade Estadual de Minas Gerais, Unidade - Carangola, Brasil, e-mail: joaocarlosgomesvalente@gmail.com

${ }_{3}$ Universidade Estadual de Minas Gerais - Unidade - Carangola, Brasil, e-mail: calacerdaabreu@gmail.com

4 Universidade Estadual de Minas Gerais - Unidade - Carangola, Brasil, e-mail: mamirandalacerda@gmail.com

5 Universidade Estadual de Minas Gerais, Unidade - Carangola, Brasil, e-mail: wagner.araújo@uemg.br
\end{abstract}

\begin{abstract}
ARTICLE INFO
Article history:

Received 2019-05-21

Accepted 2019-09-06

Available online 2019-09-06

Palavras-chave: Marketing digital. Consumidores. Ferramentas.

Keywords: Digital marketing. Consumers. Tools.

RESUMO. O presente estudo apresenta a percepção dos consumidores de supermercados de Carangola sobre as ações de comunicação de marketing digital, uma prática que tem se tornando comum nesse e em diversos seguimentos. Utilizou-se como arcabouço teórico para embasar o estudo os conceitos relacionados ao marketing e seu composto mercadológico, o marketing digital e suas respectivas ferramentas, e as principais redes sociais digitais. O estudo é caracterizado como estudo de caso do tipo descritivo e tem uma abordagem qualitativa. Como instrumentos de pesquisa utilizouse a pesquisa bibliográfica e o levantamento com utilização de questionários semiestruturados. Para análise dos dados utilizou-se a técnica da análise de conteúdo. Como resultados percebe-se que tanto clientes como empresas estão alterando sua percepção em relação as promoções mercadológicas, há uma migração no uso das ferramentas tradicionais de marketing para as ferramentas de marketing digital nas redes sociais. Estas estratégias visam aumentar a capilaridade da comunicação e estreitar o relacionamento entre empresas e clientes.
\end{abstract}

ABSTRACT. The present study presents the perception from supermarket consumers of Carangola about digital marketing communication actions, a practice that has become common in this and several segments. It was used as a theoretical framework to support the I study the concepts related to marketing and its marketing mix, digital marketing and their respective tools, and the major digital social networks. The study is characterized as descriptive case study and has a qualitative approach. As research tools bibliographic research and survey using questionnaires were used. semi-structured. For data analysis we used the technique of content analysis. Like results show that both customers and companies are changing their perception of marketing promotions, there is a migration in the use of traditional marketing tools for digital marketing tools on social networks. These strategies aim to increase the communication capillarity and strengthen the relationship between companies and customers. 


\section{INTRODUÇÃO}

A utilização da internet se popularizou no final do século $X X$, a partir de então, a internet ganhou um papel importante no cotidiano de pessoas e organizações. Através da rede mundial de comunicação milhares de pessoas se conectam em busca de informações, diversão, interação, negócios e relacionamentos, criando dessa forma novas possibilidades de atuação para as organizações.

A globalização trouxe inovações tecnológicas que revolucionaram as formas de pensar, comunicar e agir. Esses avanços permitiram maior rapidez na troca de informações e um novo espaço de relações sociais e comerciais.

Através dessas novas inovações percebe-se um elevado número de consumidores que estão diariamente conectados ao mundo virtual, exigindo assim das empresas estratégias mercadológicas para se conectarem a esses consumidores. Os limites físicos das organizações são alterados a partir da utilização da internet como canal de negócios, comunicação e relacionamento com os clientes, estabelecendo assim novas possibilidades para diminuir possíveis hiatos entre distâncias, informações e até mesmo relacionamento.

A era digital impôs às organizações adaptações em suas estratégias de marketing. Para acompanhar essa evolução as empresas passaram a utilizar também estratégias para o marketing digital. A exploração das diferentes redes sociais por parte das empresas para divulgar, aproximar-se, efetuar vendas e manter relacionamentos, elevou a importância significativa das redes sociais para os negócios, exigindo dos gestores uma atenção especial para o planejamento, execução e controle dos conteúdos que são disponibilizados nas mídias sociais. Assim, para compreender melhor esse novo cenário buscou-se através deste estudo analisar a percepção dos consumidores de supermercados da cidade de Carangola - MG sobre a comunicação de marketing digital.

\section{MARKETING}

Os conceitos e aplicações do marketing estão em constante evolução. As mudanças tecnológicas, sociais e ambientais são as principais forças que atuam para essa mudança. Kotler e Keller (2012) apresentam em sua obra uma definição da Associação Americana de Marketing (AMA) que retrata o marketing como: "a atividade, o conjunto de conhecimentos e os processos de criar, comunicar, entregar e trocar ofertas que tenham valor para consumidores, clientes, parceiros e sociedade como um todo". (KOTLER E KELLER, 2012, p. $3)$.

Las Casas, (2010) indica em sua obra que o conceito de marketing ultrapassa as relações de troca. 
Marketing é a área de conhecimento que engloba todas as atividades concernentes às relações de troca, orientadas para a satisfação dos desejos e necessidades dos consumidores, visando alcançar determinados objetivos de empresas ou indivíduos e considerando sempre o ambiente de atuação e o impacto que essas relações causam no bem-estar da sociedade. (LAS CASAS, 2010, p. 10)

Para Urdan e Urdan, (2010), o marketing é uma atividade de comercialização que envolve estímulo e geração de trocas entre duas ou mais partes, buscando satisfazer suas necessidades mutuamente. O marketing possui entre suas incumbências gerar lucro, atendendo de forma a superar as expectativas dos clientes.

Os resultados são realizar trocas, gerar valor, satisfazer o cliente e atender aos objetivos da empresa. As etapas do processo incluem, por exemplo, atividades de pesquisa de mercado, análise de concorrência, definição de posicionamento e desenvolvimento de produtos (URDAN E URDAN, 2010, p. 5 e 6$)$.

Dias (2003) relata que entre os objetivos da organização está o relacionamento com o mercado, buscando ser eficiente e eficaz na proposta estratégica.

Marketing é a função empresarial que cria continuamente valor para o cliente e gera vantagem competitiva duradoura para a empresa, por meio da gestão estratégica das variáveis controláveis de marketing: produto, preço, comunicação, distribuição (DIAS, 2003, p. 2).

Assim como a evolução tecnológica, o marketing também passou por várias transformações, alterando a visão e a preocupação das organizações. Atualmente não basta só conhecer o mercado e suprir as necessidades e desejos dos consumidores, é necessário conhecê-los e criar uma interação direta, oferecendo-lhe uma oferta personalizada, proporcionando encantamento e consequentemente sua fidelização. Nunes e Cavique (2008) relatam em sua obra:

Não basta conhecer o mercado - é preciso conhecer cada cliente (...) não basta fidelizar o cliente - é preciso interagir individualmente com ele, para Ihe proporcionar uma oferta personalizada, de valor individual, que permita a sua fidelização por encantamento total (NUNES E CAVIQUE, 2008, p. 51).

Kotler e Keller (2012) relatam que entre os objetivos da administração de marketing é conhecer e entender os clientes, determinar o público-alvo, manter e conquistar clientes, oferecer e entregar produtos de valor e adequados a suprir as necessidades, que gerem lucro para as organizações, que se vendam por si só.

A arte e a ciência de selecionar mercados-alvo e captar, manter e fidelizar clientes por meio da criação, entrega e comunicação de um valor superior 
para o cliente (...). Marketing é um processo social pelo qual indivíduos e grupos obtêm o que necessitam e desejam por meio da criação, da oferta e da livre troca de produtos de valor entre si. (KOTLER E KELLER, 2012, p. 3 e 4).

\subsection{Composto Mercadológico}

O composto mercadológico estruturado por McCarthy denominado 4P's, é utilizado como base estratégica para as ações de marketing. Essas variáveis mercadológicas precisam ser administradas pelas empresas em prol de satisfazer seus objetivos e as necessidades e desejos dos consumidores, de acordo com Tupiniquim e Freitas, (1999, p. 54):

A estratégia mercadológica do composto de marketing pode ser definida como o conjunto de variáveis controláveis que a empresa utiliza par a influenciar as respostas dos consumidores, e podem ser classificadas (segundo E. Jerome McCarthy) em quatro fatores: preço, praça, produto e promoção. (TUPINIQUIM E FREITAS, 1999, p. 54).

O preço constitui segundo Kotler e Keller (2006), do valor monetário para se adquirir um produto ou serviço. Ele é determinado por todos os custos e receitas inerentes ao bem que está se colocando à venda no mercado. Ele é quem produz receita sendo um elemento flexível e orientado pelas condições mercadológicas.

Atualmente, o preço não se restringe apenas ao valor fixado nas etiquetas, ele é também constituído através um consenso entre as empresas e seus clientes. A prática do preço teve uma mudança significativa no século $X X I$, o acesso à internet transformou a interação entre consumidores e fornecedores, fato que contribuiu muito para um efeito dominó que busca a maior eficiência na precificação (KOTLER E KELLER, 2012).

A praça ou distribuição refere-se a todas as ações e meios que são utilizados para conduzir os produtos da empresa até o consumidor. Leva-se em consideração ao determinar o P de praça o modal que será utilizado, toda parte de movimentação dos produtos e serviços e as estratégias de canal. Para Kotler e Keller (2012) os canais de distribuição constituem:

Conjuntos de organizações interdependentes envolvidas no processo de disponibilizar um bem ou serviço para uso ou consumo. Eles formam o conjunto de caminhos que um produto segue depois da produção, culminando na compra ou na utilização pelo usuário final. (KOTLER E KELLER, 2012, p. 448).

Os tipos de canais são decisivos para as organizações, pois é através deles que os produtos são distribuídos chegando até o consumidor.

O produto é um bem ou serviço disponibilizado no mercado para aquisição ou consumo dos clientes, buscando satisfazer um desejo ou necessidade (KOTLER E KELLER, 2012). Para Urdan (2010), "produto é um objeto concreto ou abstrato que satisfaz a necessidades e desejos dos consumidores". 
Existem várias ferramentas utilizadas para realizar a veiculação de um produto, serviço ou empresa. O Quadro 1, adaptado da obra de Duran (2010), apresenta as principais informações relativas a cada ferramenta mercadológica.

\begin{tabular}{l|l}
\multicolumn{2}{c}{ Quadro 1 - Ferramentas Mercadológicas - Adaptado de Duran (2010) } \\
\hline Propaganda & $\begin{array}{l}\text { Constituem diversas formas pagas de veiculação de informações ou } \\
\text { imagem da empresa, exemplos: jornais, revistas, outdoor, busdoor, } \\
\text { banner's em páginas da internet, vídeos em tv e internet, etc. }\end{array}$ \\
\hline Marketing Direto & $\begin{array}{l}\text { É uma comunicação direta entre as organizações e os clientes e } \\
\text { potenciais clientes, essa ação busca estreitar os relacionamentos } \\
\text { entre essas duas partes. }\end{array}$ \\
\hline Venda Pessoal & $\begin{array}{l}\text { Consiste na atuação do vendedor interagindo diretamente com o } \\
\text { consumidor, informando, tirando dúvidas e estimulando a compra. }\end{array}$ \\
\hline Promoção de Vendas & $\begin{array}{l}\text { Essa ferramenta reúne uma variedade de atividades que possuem } \\
\text { como objetivos acrescentar valor e automaticamente estimular a } \\
\text { compra, exemplos dessas ações: degustações, sorteios, brindes, } \\
\text { compre X leve X + 1, etc. }\end{array}$ \\
\hline Relações Públicas & $\begin{array}{l}\text { Refere ao acompanhamento das perspectivas dos clientes, } \\
\text { acionistas, fornecedores, distribuidores, funcionários em relação à } \\
\text { empresa e o produto, ouvindo as solicitações, criando e mantendo } \\
\text { relações positivas através de suas ações, criando uma imagem } \\
\text { positiva perante o público. }\end{array}$ \\
\hline Eventos \\
experiências & $\begin{array}{l}\text { Constituem ações, eventos, experiências com a marca ou a } \\
\text { organização. Esse tipo de ação cria uma familiaridade entre clientes } \\
\text { e as organizações. }\end{array}$ \\
\hline
\end{tabular}

Fonte: Próprios autores (2019)

A promoção consiste na divulgação e comunicação do produto no mercado-alvo através de promoção de vendas, publicidade, relações públicas, entre outros (KOTLER e KELLER 2006 e LAS CASAS, 2010). A definição das mídias de comunicação do $P$ de promoção é determinante para propagação do produto de maneira eficaz, a encantar os clientes e a adquirir sua preferência, obtendo assim os objetivos esperados pela organização, Urdan (2010, p. 246) relata ser importante "definir a combinação mais eficaz e eficiente de atividades, mensagens e mídias para atingir seus objetivos".

Kotler e Keller (2012, p. 542) revelam que "os objetivos da propaganda devem resultar de decisões previamente tomadas sobre o mercado-alvo, o posicionamento da marca e o plano de marketing". Há vários veículos de propaganda como: televisão, impressas, rádio, jornais, outdoor, mala direta, internet, folhetos, revistas, entre outros, a decisão de qual utilizar 
dever ser bem analisadas, para que possam impactar e resultar num melhor retorno do público-alvo. "É preciso tomar decisões sobre cobertura, frequência e impacto; escolher entre os principais tipos de mídia; selecionar veículos de comunicação específicos" (KOTLER E KELLER, 2012, p. 548).

Para Santiago ( 2012), promoção é promover, divulgar os produtos buscando atingir os consumidores e mercado-alvo com intuito de encantá-los e persuadi-los a desejar comprar seus produtos, utilizando vários tipos de estratégias de mídias como as propagandas em televisão que tem alta cobertura de público, o rádio chegando a pequenas cidades e regiões, já as revistas e mala direta uma mídia dirigida a um público específico, os jornais e os outdoors propagandas ao ar livre.

\subsection{Marketing Digital}

O conceito de marketing digital está relacionado ao uso das tecnologias digitais para criar comunicações integradas, direcionadas e mensuráveis visando captar e reter consumidores, ao mesmo tempo em que constroem relações profundas com os mesmos (Digital Marketing Institute Wymbs, 2011). Outra definição, diz que "marketing digital são ações de marketing que utilizam meios digitais como plataforma principal da estratégia de marketing". (OKABE, 2009, p. 1)

Ao contrário do que se pode imaginar, o marketing digital não é um novo marketing, o e-marketing é uma evolução das tradicionais ações de marketing para as plataformas digitais, visando, alcançar os consumidores que também estão presentes na Internet (TORRES, 2010).

Segundo o site INTERNET WORLD STATS (2018), mais de 4 bilhões de usuários acessaram a internet em dezembro de 2017 , isso representa mais de $54,4 \%$ da população mundial. Desta forma, é importante para as organizações manterem ações de marketing na rede mundial de computadores. Kotler (2006) relata que é importante que as empresas acompanhem o ritmo da evolução tecnológica, buscando mitigar suas velhas práticas de marketing e acompanhando as novas tendências.

A possibilidade de se conectarem com qualquer parte do mundo através da internet, sejam através de sites, blogs, redes sociais ou outros, levaram aos consumidores mais informações e com isso mais possibilidades de efetuarem relações de troca. De acordo com Vaz (2008, p. 54) "o marketing destes novos tempos interage com o consumidor de maneira completa e faz dele, em tempo real, seu objeto de estudo e de direcionamento de suas táticas".

O marketing digital é uma forma das empresas melhorarem o relacionamento com os seus clientes, as ferramentas digitais ajudam proporcionar essa aproximação entre usuário e empresa. Por tanto, as empresas devem promover aos seus clientes conteúdos relevantes, aperfeiçoamento do seu negócio, além de interagir em tempo real, com informações 
importantes da empresa e do produto (KOTLER, 2010). Neste contexto, as empresas devem buscar métodos adequados para poderem manter-se ativas no mercado/Internet buscando interagir com esse novo comportamento de seus consumidores (TORRES, 2009).

De acordo com Siqueira (2006) os gestores de marketing podem utilizar diferentes ações como publicidade on-line, e-mail marketing, pesquisas on-line, marketing viral, marketing de conteúdo, marketing nas mídias sociais para criar uma presença efetiva na internet. Para o autor a publicidade on-line tem por objetivo divulgar a marca, produto, serviço ou organização através de banners, vídeos, imagens. O e-mail marketing é basicamente a evolução do antigo marketing direto, é uma das ações mais utilizadas pelas empresas, porém seus resultados não são atraentes visto que as empresas não aplicam corretamente a ferramenta. As pesquisas on-line são utilizadas para estabelecer o sistema de inteligência em marketing, buscando assim conhecer os consumidores, potencias clientes, concorrentes e o mercado em si. O marketing viral é o conhecido boca a boca só que na internet, os gestores de marketing irão criar conteúdos que proporcionarão repercussão nas redes. O marketing de conteúdo tem por objetivo e atrativo elaborar conteúdos úteis e relevantes para atrair e reter clientes, geralmente esses conteúdos são distribuídos por blogs e redes sociais. Marketing nas mídias sociais visa criar relacionamentos entre a empresa e o consumidor.

Segundo Vaz (2011, p. 297) "o consumidor mudou com a tecnologia e a tecnologia mudou com o consumidor". A partir dessa premissa, Vaz (2011) desenvolveu a metodologia dos 8P's do marketing digital. Essa metodologia tem por intuito orientar as organizações para que possam extrair o máximo de suas próprias ações e consequentemente do comportamento dos consumidores, buscando ser mais eficiente e eficaz nas estratégias mercadológicas, ajudando a manter, corrigir e aperfeiçoar os relacionamentos com os consumidores. O Quadro 2 apresenta informações sobre cada elemento dos 8P's adaptado da obra de Vaz (2011).

\section{Quadro 2 - 8 P'S - Adaptado de Vaz (2011)}

\begin{tabular}{|l|l|}
\hline Pesquisa & $\begin{array}{l}\text { Pesquisar o mercado, filtrar os hábitos de consumo dos usuários, colher } \\
\text { informações em suas redes sociais, saber o que o consumidor deseja, } \\
\text { definir o público-alvo e atingi-lo com uma comunicação correta e } \\
\text { personalizada. }\end{array}$ \\
\hline Planejamento & $\begin{array}{l}\text { Elaboração de documento bem definido para todos os membros da equipe, } \\
\text { pois será a diretriz de todo projeto. Este deverá ser bem estudado, } \\
\text { implementado e controlado, deverá possuir explicações minuciosas sobre } \\
\text { cada etapa dos 8P's, para seja executado conforme o que foi idealizado. }\end{array}$ \\
\hline Produção & $\begin{array}{l}\text { A criação do site, canal ou perfil, deve ser concentrada, estruturada, } \\
\text { otimizada, de boa usabilidade, funcional, de conteúdo agradável, com } \\
\text { intuito de atrair os consumidores, retendo-os e persuadindo-os para que se }\end{array}$ \\
\hline
\end{tabular}




\begin{tabular}{|l|l|}
\hline Publicação & $\begin{array}{l}\text { tornem clientes que visualizem, comprem e fidelizem-se com a empresa ou } \\
\text { produto. }\end{array}$ \\
\hline Promoção & $\begin{array}{l}\text { O conteúdo que será disponibilizado para o mercado e o consumidor } \\
\text { informações claras, objetivas e detalhadas, através de áudios, vídeos } \\
\text { explicativos, fotos, gerando credibilidade, aumentando a fidelização e o } \\
\text { relacionamento empresa/cliente. }\end{array}$ \\
\hline Propagação & $\begin{array}{l}\text { Essa estratégia busca transformar o consumidor em veículo de } \\
\text { comunicação e propagação da marca, realizando campanhas promocionais } \\
\text { on-line, fortalecendo e promovendo a marca no mercado, envolvendo-o } \\
\text { para que esse se transforme em um multiplicador. . }\end{array}$ \\
\hline Personalização \\
$\begin{array}{l}\text { Divulgação nas redes sociais, quanto mais propagado for o conteúdo da } \\
\text { marca, mais presença on-line ela terá e consequentemente ganhará mais } \\
\text { reputação e capital social, fortalecendo assim sua positividade e } \\
\text { credibilidade alcançando maior lucratividade. }\end{array}$ \\
$\begin{array}{l}\text { É importante que a empresa crie experiências segmentadas por grupos } \\
\text { específicos criando ações personalizadas e uma experiência única, } \\
\text { tratando os consumidores de maneira individual, criando estratégias para } \\
\text { fidelizar mais clientes. }\end{array}$ \\
\hline Precisão \\
$\begin{array}{l}\text { É importante mensurar os resultados do custo-benefício e retorno do } \\
\text { investimento, exibindo os resultados alcançados, através da extração de } \\
\text { dados, com a finalidade de interpretá-los e transformá-los em informações } \\
\text { precisas. }\end{array}$ \\
\hline
\end{tabular}

Fonte: Próprios autores (2019)

Através dessa orientação para o 8P's é possível fazer uma análise de mercado, segmentação de mercado, pesquisas de marketing, plano de marketing com mais facilidade e rapidez (VAZ, 2011).

\subsection{Ferramentas do Marketing Digital}

As mídias sociais Facebook, Instagram, Twitter, Linkedin, YouTube, Blogs, WhatsApp são uma oportunidade a mais, para as organizações se relacionarem com o mercado de forma competitiva (MATHEUS, 2014). As mídias sociais transformaram essa relação, pois constituem verdadeiros campos para que os consumidores pesquisem, exponham suas opiniões, queixas, frustações e satisfações. Por outro lado, permitem que as organizações apresentem e ofereceram seus produtos, marcas ou serviços, através de fotos e exibição de vídeos, campanhas, anúncios de eventos e lançamentos, aproveitando o grande número de usuários conectados onde eles compartilham suas experiências, informações e opiniões sobre os produtos (MATHEUS, 2014). Torres (2010, p. 7) relata que o gestor de marketing deve "ter uma estratégia coerente, eficiente e eficaz, que transforme a internet em um aliado do seu negócio hoje, amanhã e sempre". Segundo Torres (2010): 
O marketing digital está se tornando cada dia mais importante para os negócios e para as empresas. Não por uma questão de tecnologia, mas uma mudança no comportamento do consumidor, que está utilizando cada vez mais a internet como meio de comunicação, informação, relacionamento e entretenimento (TORRES, 2010, p. 7).

Torres (2010), afirma que a empresa deve estar presente onde o cliente está, e atualmente eles estão na internet. Assim, é importante que o gestor aproveite bem a rede para ampliar a exposição de seus produtos e marcas, empenhando-se na comunicação e no relacionamento com seus clientes. "Produzir e divulgar conteúdo útil e relevante na Internet para atrair atenção e conquistar o consumidor on-line" (TORRES, 2010, p. 12).

Para atrair e conquistar seus clientes as organizações precisam se tornar visíveis, isto posto, é importante que ela pesquise e defina o público alvo, verifique em quais as redes sociais eles se encontram (Blogs, Twitter, Facebook, Myspace, YouTube, Linkedin, etc.), planeje e divulgue conteúdo úteis e contribua para aumentar a informação e interação entre a empresa e os clientes. É ainda importante que o gestor monitore seu site, verifique as interações e acessos, assim como deve "manter-se informado sobre o futuro e as tendências na Internet, no Marketing digital e nas Mídias Sociais" (TORRES 2010, p. 51).

Para Torres (2010, p. 52) cabe ao gestor "abraçar as tecnologias ligadas a Internet e usá-las" para alavancar seus negócios. Ferramentas como Google Analytics servem para emissão de relatórios de monitorização, Google Maps para localização e descrição da sua empresa, Webmasters proporcionam informações de como seu site será visto pelos usuários, Google Docs pode ser utilizado para realizar pesquisas diretamente com seus clientes.

As mídias sociais vêm se tornando cada vez mais presentes no que tange o marketing e suas ferramentas. Estudos apresentam essas mídias como grandes ferramentas para as organizações, com grande relevância de mercado e um fator decisivo na fidelização de clientes e busca por futuros, segundo Kotler e Keller (2012, p. 589):

As mídias sociais dão às empresas voz e presença pública na Web, além de reforçarem outras atividades de comunicação. Por causa de seu imediatismo diário, elas também podem incentivar as empresas a se manterem inovadoras e relevantes.

\subsubsection{Principais Redes Sociais Utilizadas para o Marketing Digital}

O Twitter é uma ferramenta baseada em postagens curtas, caracterizada como micro blog, podendo criar e compartilhar ideias e informações. As empresas aproveitam desse canal para divulgar seus produtos e serviços, medir os impactos de suas campanhas, a influência e a ação resultante de sua publicidade. "O Twitter é uma mídia social que mistura diversos elementos de comunicação e relacionamento e podem ser utilizados para complementar suas 
ações de marketing de conteúdo e para integrar a comunicação as demais mídias sociais" (TORRES, 2009, p. 152).

Linkedin é uma rede social de negócios, é utilizada para apresentação do perfil do profissional individual, e aproveitado pelas empresas para criarem sites de relacionamentos segmentados entre elas (ALMEIDA JÚNIOR, et. al., 2017).

Facebook é a mídia mais usada pelos usuários no mundo, possui um feed de notícias, possibilitando postagens e compartilhamento de vídeos, fotos, entre outras (ALMEIDA JÚNIOR, et. al., 2017). E tem outras funcionalidades como postar textos, links, criar grupos, perfis e páginas, além do espaço para anúncios (SANTOS E BARROS, 2018).

Instagram criado em 2010, oferece oportunidade aos usuários de compartilhar e publicar imagens e vídeos pessoais, de produtos ou marcas, possibilitando o comprometimento dos consumidores com as marcas e a interação entre eles (ARAGÃO, et. al., 2016). Segundo Santos e Barros (2018), além de tirar e compartilhar fotos, conta também a com a ferramenta Stories que possibilita realizar transmissões ao vivo.

Blog é uma ferramenta de publicação de texto, que permite atualização rápida do seu conteúdo amplamente para o público, através de divulgação de anúncio, informações úteis e compartilhamento de opiniões de um determinado público sobre um assunto específico. Para Paz (2003, p. 67), "o blog é um formato de publicação online que desperta interesse por suas ditas simplicidade e facilidade de uso".

WhatsApp é o aplicativo utilizado para envio de mensagens, vídeos, fotos, áudios e chamadas de voz de vídeo entre os telefones de forma rápida e de fácil acesso, sendo, necessário estar conectado à internet. Ferreira e Flores (2018) relatam que o WhatsApp chegou ao mercado, possibilitando novas oportunidades de trabalho, comunicação, relacionamento, compras, vendas, entre outros. Diversas empresas estão aderindo à rede social para divulgar e alavancar suas vendas e estreitar seu relacionamento com os clientes. "O aplicativo pode trazer muitos benefícios para a organização, facilitando e contribuindo nas vendas de produtos e nas prestações de serviços, além ser muito ágil e rápido nas trocas de mensagens, sem contar nas possibilidades de chamadas de voz" (FERREIRA e FLORES, 2018, p. 88).

YouTube é um canal que permiti o compartilhamento, a divulgação e postagem vídeos, receber avaliações e comentários. (ROBERTO, 2009). Para Santos e Barros (2018) através do canal é possível introduzir imagem, descrição, marca, avaliação e comentários dos usuários sobre o conteúdo dos vídeos, além da interação com outras redes sociais.

\section{PROCEDIMENTOS METODOLÓGICOS}

Utilizou-se para elaboração deste estudo uma abordagem qualitativa. Empregou-se como técnica de estudo, o estudo de caso com pesquisas bibliográficas e levantamento com pesquisa semiestruturada. A análise se deu através da técnica de análise de conteúdo. 
A pesquisa bibliográfica em acervos on-line e físicos possibilitou aos pesquisadores maior familiaridade com o tema e sistematização do conteúdo pesquisado (GIL, 2002). Através do levantamento buscou-se conhecer a percepção dos sujeitos sociais, utilizou-se questionários semiestruturados para interrogação direta dos participantes. Aplicou-se 122 questionários, entre os dias 20 a 24 do mês julho do ano de 2019, na porta de dois diferentes supermercados. A eleição dos dois supermercados se deu a partir do número de check out's, elegeu-se os supermercados que possuíam mais de 4 check out's.

Para análise dos dados utilizou-se a técnica de análise de conteúdo. Elaborou-se 3 categorias de análises para sistematizar os dados primários. De acordo com Bardin (1977) a análise de conteúdo ao mesmo tempo em que exige do pesquisador uma atenção especial aos dados ela é uma técnica que reproduz aquilo que os dados realmente dizem.

\section{ANÁLISE DOS RESULTADOS}

Inicialmente procurou-se identificar o perfil dos pesquisados e sua relação com as redes sociais. Aproximadamente $38,9 \%$ dos entrevistados possuem de 17 a 30 anos, 36,8\% possuem de 31 a 45 anos, 24,3\% possuem de 46 a 60 anos. Quando questionados sobre a utilização das redes sociais, todos os entrevistados disseram utilizar pelo menos um tipo de rede social digital, sendo que $96 \%$ deles utilizam o Whatsapp, $77 \%$ o Facebook, $67,2 \%$ o Instagran, 7,4\% o Twiter, 6,6\% o Linkedin, diversos entrevistados possuem mais de uma rede social.

Identificou-se posteriormente que aproximadamente $76 \%$ dos respondentes buscam promoções de produtos do supermercado em redes sociais, seguidos folder $32,8 \%$, cartazes no próprio mercado $29,5 \%$ e por fim televisão $2,5 \%$. É importante informar que os entrevistados puderam optar por um ou mais ferramentas de comunicação.

Percebe-se que as novas ferramentas de comunicação, principalmente as redes sociais sobressaem em relação às ferramentas tradicionais, mostrando que além de comunicarem a promoção em si, podem se tornar um canal de comunicação mais interativo com os clientes. Entretanto a análise releva que aproximadamente 1/3 dos entrevistados ainda buscam promoções através de folders, fato que deve ser contextualizado com o cenário deste estudo de caso.

Para melhor compreensão da utilização dessas novas ferramentas de comunicação digital como ferramenta de promoção, averigou-se com os entrevistados quais são os meios mais acessados por eles. Aproximadamente $62 \%$ dos entrevistados utilizam o Facebook, aproximadamente 57\% utilizam o Instagram, 50,8\% utilizam o Whatsapp e 16,4\% utilizam os sites de empresas. No momento da pesquisa, possibilitou-se aos entrevistados responder mais de um item, levando em consideração que as organizações que participam do estudo de caso, possuem diversas plataformas de comunição digital. Nota-se através desses dados que 
as ferramentas de comunicação mais remoto e que possuem outros conteúdos como Facebook, Instragram e Whatsapp são mais utilizados que o site institucional.

Analisou-se também a opinião dos entrevistados sobre a utilização das redes sociais como ferramenta de promoção por parte dos supermercados (Figura 1). Percebe-se que aproximadamente $60 \%$ consideram ótima a utilização dessas ferramentas para divulgação de promoções.

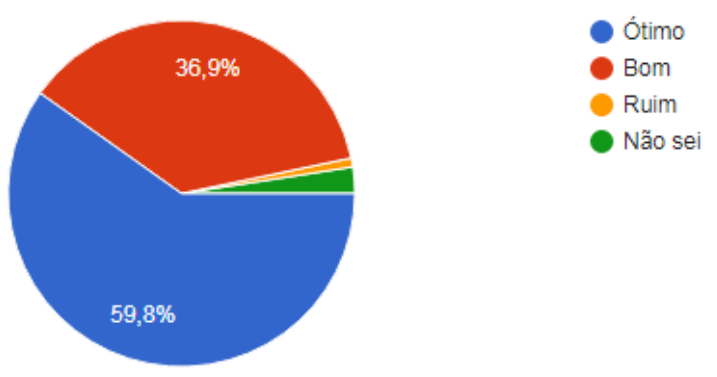

Figura 1 - Utilização das redes sociais como ferramenta de promoção Fonte: próprios autores (2019)

Levantou-se a questão sobre a frequência com que esses clientes procuram ou recebem as informações sobre promoções dos supermercados (Figura 2). Apurou-se que a grande maioria, cerca de $60 \%$ possuem contato com essas promoções por meio digital 1 vez por semana, aproximadamente 30\% recebem ou pesquisam essas informações 1 ou 2 vezes por semana e cerca de $10 \%$ se familiarizam com elas todos os dias.
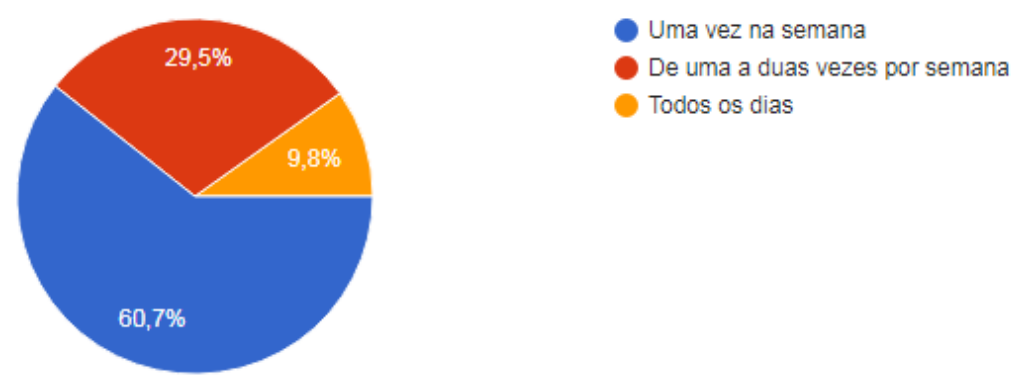

Todos os dias

Figura 2 - Frequência de recebimento de promoções

Fonte: próprios autores (2019)

Avaliou-se também a opinião dos pesquisados sobre a divulgação, o conteúdo, a forma como as promoções são divulgadas nas redes sociais. Considerando uma escala de: ótimo, bom, regular, ruim, péssimo e não sabe opinar, apurou os seguintes percentuais descritos no gráfico abaixo. Nota-se que aproximadamente $50 \%$ dos entrevistados avaliam as divulgações como boa, superando a o ótimo em 18\% e 37\% o regular (Figura 3). 


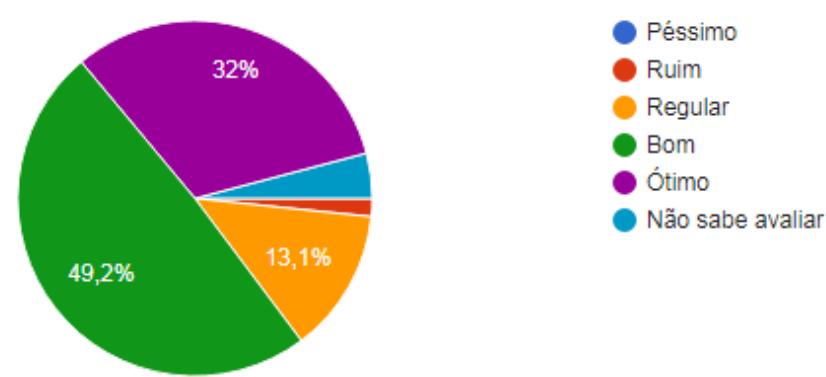

\section{Figura 3 - Opinião sobre o conteúdo apresentado nas redes sociais dos supermercados}

Fonte: próprios autores (2019)

Quando questionados se as novas formas de comunicação da empresa através das redes sociais trouxeram uma proximidade entre empresa/clientes verificou-se que $97,5 \%$ dos pesquisados disseram que sim, essas novas ferramentas aproximaram os clientes das empresas e empresas dos clientes.

Averiguou-se em uma escala de 1 a 5, onde mais próximo de 1 não ajuda e mais próximo de 5 ajuda, o quanto os entrevistados concordam que as redes sociais ajudam aos supermercados a ganharem mais espaço no relacionamento com o cliente. Cerca de $80 \%$ se posicionaram na escala entre os números 4 e 5, consideram que sim, as redes sociais ajudam no relacionamento com o cliente. $E$ apenas 2,4\% ficaram entre os números 1 e 2, onde consideram que as redes sociais não ajudam no relacionamento com o cliente. Corroborando a análise da pergunta anterior relacionada à proximidade entre a empresa e o cliente, e o cliente e a empresa (Figura 4).

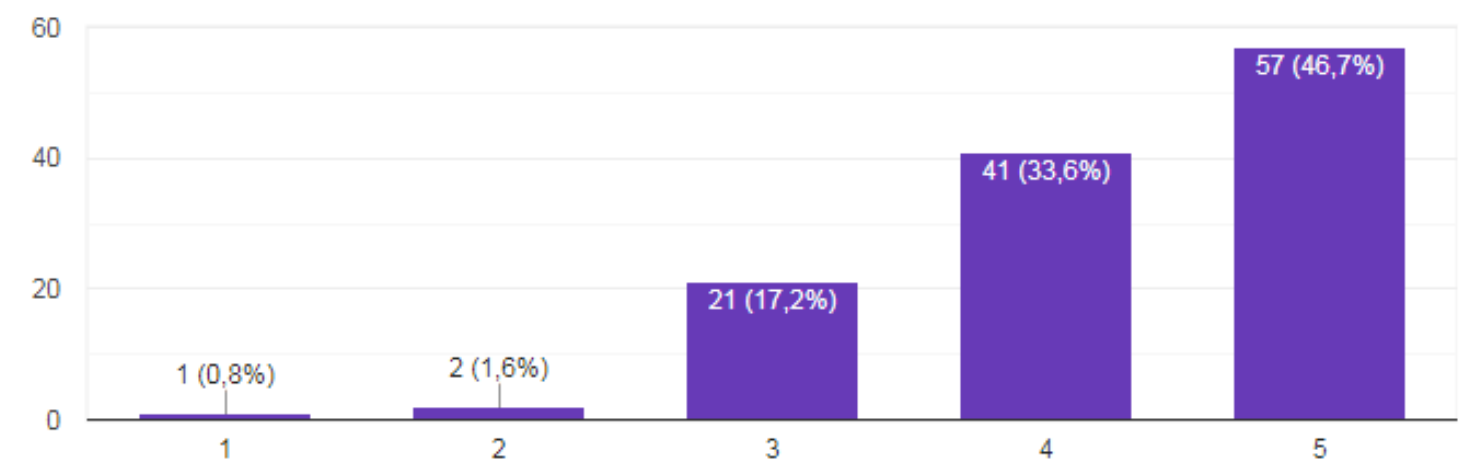

Figura 4 - Utilização das redes sociais para relacionamento com os clientes Fonte: próprios autores (2019)

Através da análise dos dados percebe-se que as redes sociais permitiram maior visibilidade da empresa, cerca de $94 \%$ consideram que as redes sociais permitiram uma divulgação mais efetiva das promoções e da empresa em si. 


\section{CONCLUSÃO}

Em tempos em que a tecnologia se faz presente cada vez mais no cotidiano de todos, pode se constatar que ela tem proporcionado novas possibilidades de comunicação, negócios e relacionamentos entre empresas e clientes, isto particularmente contribui para a conquista e a fidelização de clientes.

Os consumidores estão cada vez mais informados, conectados e exigentes, isso exige das empresas novas estratégias para acompanhar o novo comportamento dos consumidores. Os estudos estão revelando que estes consumidores estão cada vez mais conectados e que a velocidade e o conteúdo das informações têm feito um diferencial para as empresas que desejam acompanhar o ritmo desses novos consumidores.

Assim, as empresas podem e devem utilizar-se das novas tecnologias e ferramentas de comunicação para se fazer presente no cotidiano dos consumidores. As empresas podem utilizar as redes sociais em especial, para diminuir a distância entre sua organização e os clientes, muitas vezes rompendo a barreira física que os separa, criando espaços para um relacionamento profícuo entre as partes.

As ferramentas digitais possibilitaram as organizações aumentar sua capilaridade e frequência de contato com o cliente. Pode-se através delas criar uma interação com diferentes públicos e com diferentes frequências inclusive e de preferência instantâneas.

É importante que as empresas busquem otimizar suas estratégias de marketing digital para diferenciar-se dos concorrentes e aproximar-se cada vez mais dos seus clientes e potenciais consumidores. Verifica-se que o marketing digital possibilita comunicação, interação, negociação e fidelização, ações importantes para o sucesso de qualquer estratégia mercadológica.

Nota-se através deste estudo que todos os consumidores entrevistados possuem pelo menos uma rede social e muitos deles gostam de serem informados sobre promoções de supermercados através dessas redes, reforçando assim a necessidade de se manter a interação entre essas empresas e os clientes. Avaliou-se o conteúdo das promoções disponibilizadas nas mídias sociais e notou-se que as empresas ainda precisam melhorar nesse quesito para atrair e ainda mais a atenção e interesse de seus clientes.

Por se tratar de ferramentas novas e com uma interação constante por parte de diferentes atores: clientes, concorrentes diretos e indiretos, é importante que as organizações estejam em constante atualização para ajustar suas estratégias mercadológicas a essas novas demandas. As empresas que resolverem empreender nesse cenário deveram estar dispostas a acompanhar a nova era digital.

Recomenda-se novas pesquisas e aprofundamento do tema para generalizações, visto que esse artigo aborda a particularidade de um caso. 


\section{REFERÊNCIAS}

ALMEIDA JÚNIOR, Altamiro Lacerda, et. al.. E-Marketing: Um Estudo de Caso em Empresas e Comércio do Bairro Centro de Carangola - MG. 2017. Disponível em <https:www.escavador.com/sobre/224543008/tais-cristina-silva>. Acesso em 30 de abr. 2019

ARAGÃO, Fernanda Bôto Paz, et. al. Curtiu, Comentou, Comprou. A mídia Social Digital $\begin{array}{llllll}\text { Instagram } & \mathbf{e} & \mathbf{0} & \text { Consumo. } & 2016 . & \text { Disponível }\end{array}$ <periódicos.unifor.br/rca/article/view/3979/4698>. Acesso em 01 de mai. de 2019.

BARDIN, Laurence. Análise de Conteúdo. Lisboa Portugal: Edições 70, 1977. DIAS, Sergio Roberto. Gestão de Marketing. Professores do Departamento de Mercadologia da FGV-EAESP e Convidados. São Paulo: Editora Saraiva, 2003.

\section{ESTATÍSTICA DO MUNDO DA INTERNET: DIRETÓRIO DE SITES. INTERNET WORLD STATS: WEB SITE DIRECTORY. Disponível em: $<\mathrm{https}: / /$ www.internetworldstats.com/\%20https://translate.google.com/translate?hl=pt- \\ $\mathrm{BR} \& s \mathrm{~s}=\mathrm{en} \& \mathrm{u}=\mathrm{https}: / / \mathrm{www}$.internetworldstats.com/\&prev=search>. Acesso em: 10 jun. 2019.}

FERREIRA, João Batista e FLORES, Izabela Fernandes. Tecnologias Móveis e Redes Sociais no Mercado de Trabalho: Visão dos Gestores Organizacionais. 2018. Disponível em: http://www.inteligenciacompetitivarev.com.br/ojs/index.pho/rev> ISSN: 2236-210X DOI 10.24883. Acesso em 14 de maio de 2019.

GIL, Antônio Carlos. Como Elaborar Projetos de Pesquisa. 4. ed. São Paulo: Atlas, 2002.

KOTLER, Philip e KELLER, Kevin Lane. Administração de Marketing. A bíblia do Marketing. 12ª̣ed. São Paulo: Editora Pearson Prentice Hall, 2006.

KOTLER, Philip e KELLER, Kevin Lane. Administração de Marketing. 14ªed. São Paulo: Editora Pearson Education do Brasil, 2012.

KOTLER, Philip. Marketing 3.0: Tradução de Ana Beatriz Rodrigues. Rio de Janeiro: Elsevier, 2010.

LAS CASAS, Alexandre Luzzi. Marketing de Serviços. 5ª ed. São Paulo: Editora Atlas, 2010.

MATHEUS, Felipe. A hora do Marketing Digital: A internet mudou o marketing. Preparese. Entenda como usar marketing digital em seu negócio, identificando e corrigindo problemas em sua presença digital, usando estratégias para melhorar seus resultados na internet. Edição 1. Editora: Independente ISBN: B00PITM21S, Ano: 2014.

NUNES, João Coelho e CAVIQUE, Luís. Plano de Marketing Estratégia em Ação: Um instrumento prático para a atividade empresarial. Portugal: Editora Alfragide Publicações Dom Quixote, 2008.

OKABE, Márcio. O que é Marketing Digital. 2009. Disponível em: <http://www.konfide.com.br/marketing-on-line/o-que-e-marketing-digital>. Acesso em 15 mai. 2019.

PAZ, Carolina Rodrigues. A Cultura Blog: questões introdutórias. Revista FAMECOS, n. 22, $2003 . \quad$ Disponível em: <revistaseletronicas.pucrs.br/ojs/index.php/revistafamecos/article/.../2497> Acesso em 18 de mai. de 2019. 
ROBERTO, Maciel Laís. A Influência das Redes Sociais na Comunicação Organizacional. Artigo (Bacharel em Comunicação Social) - Universidade Nove de Julho. São Paulo, 2009. Disponível em: <https://www.aberje.com.br/monografias/redessociais_comorganiz.pdf>. Acesso em 15 de mai. de 2019.

SANTIAGO, Marcelo Piragibe. Gestão de Marketing Curitiba. Editora IESDE Brasil S.A., 2012.

SANTOS, Laura Amanda Miro e BARROS, Silas Almeida. Marketing Digital: Uma ferramenta estratégica de comunicação entre empresas e consumidores. 2018. Disponível em $<$ https://ri.cesmac.edu.br/bitstream/tede/327/1/Marketing\%20digital\%20uma\%20ferramenta $\% 20$ estrat\%C3\%A9gica\%20de\%20comunica\%C3\%A7\%C3\%A30\%20entre\%20empresas\% 20 e\%20consumidores.pdf >. Acesso em 15 mai. 2019.

SIQUEIRA, Ito. Marketing Conceitos para organizações e pessoas. Creative Commons. Feira de Santana, 2006.

TORRES, Cláudio. A bíblia do Marketing Digital: Tudo o que você quis saber sobre Marketing e Publicidade na internet e não tinha a quem perguntar. São Paulo: Novatec Editora Ltda, 2009.

TORRES, Cláudio. Guia Prático de Marketing na Internet para Pequenas Empresas: Dicas pra posicionar o seu negócio e conquistar novos clientes na Internet. São Paulo: Copyright Novatec Editora, 2010.

TUPINIQUIM, Armando Correa e FREITAS, Sebastião Nelson. Marketing Básico e Descomplicado. São Paulo: Editora STS Publicações e Serviços Ltda., 1999.

URDAN, Fábio Torres e URDAN, André Torres. Gestão do Composto de Marketing. Editora Atlas, 2006.

VAZ, Adolpho Conrado. Google Marketing: O Guia Definitivo do Marketing Digital. São Paulo: Editora Novatec, 2008.

VAZ, Adolpho Conrado. Os 8P's do Marketing Digital: O Guia Estratégico de Marketing Digital. São Paulo: Editora Novatec, 2011. 